\title{
On a Fuzzy Completely Closed Filter with Respect of Element in a BH-algebra
}

\author{
Mohsin Shaalan Abdalhussein \\ College of physical planning\Regional Planning Department \\ University of Kufa, Iraq \\ Email: mohsins.alakayshee [AT] uokufa.edu.iq
}

\begin{abstract}
In this paper, we introduce a new notion that we call a fuzzy completely closed filter with respect of an element in a BH-algebra, and we link this notion with notions filter and ideal of BH-algebra, We give some properties of fuzzy completely closed filter with respect of an element and we study properties of it.
\end{abstract}

Keywords - fuzzy completely closed filter with respect of an element, BH-algebra, fuzzy filter, fuzzy ideal, fuzzy completely closed filter and fuzzy completely closed filter.

\section{INTRODUCTION}

The notion of a BCK-algebras and a BCI-algebras was formulated first in 1966 [6] by (Y.Imai) and (K.Iseki). In 1991, C. S. Hoo introduced the notions of a filter and closed filter of a BCI-algebra[2].In 1996, M. A. Chaudhry and H. F-Ud-Din studied the concepts of filter and closed filter of a BCH-algebra[7]. In the same year, (J.Neggers) introduced the notion of d-algebra[5]. In 1998, Y.B.Jun, E.H.Roh and H.S.Kim introduced a new notion, called a BH-algebra[11]. In 2012, H.H.Abass and H.A.Dahham introduced the notions of a completely closed ideal and completely closed ideal with respect to an element of a $\mathrm{BH}$-algebra[3]. In this paper, we introduced the notions as we mentioned in the abstract. On the other hand, we will mention the development of a fuzzy set, fuzzy subalgebra, fuzzy ideals, fuzzy closed ideals and some other types of fuzzy ideals. In 1965, L. A. Zadeh introduced the notion of a Fuzzy subset of a set as a method for representing uncertainty in real physical world[12]. In 1991, O. G. Xi applied the concept of fuzzy sets to the BCKalgebras[13]. In 1993, Y. B. Jun was the first author who solved the problem of classifying fuzzy ideals by their family of level ideals in BCK(BCI)-algebras[15]. In the same year, Y. B. Jun introduced the notion of closed fuzzy ideals in BCIalgebras[16]. In 1994, Y. B. Jun and J. Meng introduced the notion of fuzzy p-ideals in BCI-algebras[14]. In 1999, Y. B. Jun introduced the notion of Fuzzy closed ideals in BCH-algebras[17]. In 2002, C. Lele, C. Wu and T.Mamadou introduced the notion of Fuzzy filter in BCI-algebras[6]. In 2009, A. B. Saeid and M. A. Rezvani . In 2011, H. H. Abass and H. M. A.Saeed introduced the notion of Fuzzy closed ideals with respect to an element of BH-algebras[10]. In 2012, H. H. Abass and H. A. Dahham, Some Types of Fuzzy Ideal With Respect To an Element Of a BG-Algebra[9] .

\section{PRELIMINARIES}

In this section, we review some basic definitions and notations of $\mathrm{BH}$-algebras, fuzzy completely closed filter, filter, ideals and other notions, that we need in our work.

\section{Definition (1.1) [12]:}

Let $\mathrm{X}$ be a non-empty set. A fuzzy set $\mathrm{A}$ in $\mathrm{X}$ (a fuzzy subset of $\mathrm{X}$ ) is a function from $\mathrm{X}$ into the closed interval $[0,1]$ of the real number.

Definition (1.2) [8]:

Let $\mathrm{A}$ and $\mathrm{B}$ be two fuzzy sets in $\mathrm{X}$, then :

1. $(A \cap B)(x)=\min \{A(x), B(x)\}$, for all $x \in X$.

2. $(A \cup B)(x)=\max \{A(x), B(x)\}$, for all $x \in X$.

$A \cap B$ and $A \cup B$ are fuzzy sets in $X$. 
In general, if $\{A \alpha, \alpha \in \Lambda\}$ is a family of fuzzy sets in $X$, the :

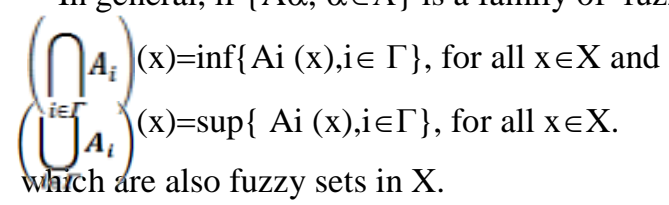

Definition ( 1.3 ) [5] :

$\mathrm{A} \mathrm{BH}$-algebra is a nonempty set $\mathrm{X}$ with a constant 0 and a binary operation"*" satisfying the following conditions:

1) $\mathrm{x}^{*} \mathrm{x}=0, \forall \mathrm{x} \in \mathrm{X}$.

2) $\mathrm{x}^{*} \mathrm{y}=0$ and $\mathrm{y}^{*} \mathrm{x}=0$ imply $\mathrm{x}=\mathrm{y}, \forall \mathrm{x}, \mathrm{y} \in \mathrm{X}$.

3) $\mathrm{x} * 0=\mathrm{x}, \forall \mathrm{x} \in \mathrm{X}$.

Example (1.4)[4]:

Let $X=\{0,1,2\}$ be a set with the following table:

\begin{tabular}{|c|c|c|c|}
\hline$*$ & 0 & 1 & 2 \\
\hline 0 & 0 & 1 & 2 \\
\hline 1 & 1 & 0 & 1 \\
\hline 2 & 2 & 2 & 0 \\
\hline
\end{tabular}

Then $\left(\mathrm{X},{ }^{*}, 0\right)$ is a $\mathrm{BH}$-algebra.

Definition (1.5)[9]:

A BH-algebra $\mathrm{X}$ is called an associative $\mathrm{BH}-$ algebra if:

$(\mathrm{x} * \mathrm{y}) * \mathrm{z}=\mathrm{x} *(\mathrm{y} * \mathrm{z})$, for all $\mathrm{x}, \mathrm{y}, \mathrm{z} \in \mathrm{X}$.

Definition (1.6)[9]:

Let $\mathrm{X}$ be a $\mathrm{BH}$-algebra and $\mathrm{b} \in \mathrm{X}$, a filter $\mathrm{F}$ is called a completely closed filter with respect to $\mathrm{b}$ (denoted by $\mathrm{b}$ completely closed filter) if $\mathrm{b}^{*}\left(\mathrm{x}^{*} \mathrm{y}\right) \in \mathrm{F} \forall \mathrm{x}, \mathrm{y} \in \mathrm{F}$

\section{Definition (1.7)[19] :}

A fuzzy set $M$ in a BH-algebra $X$ is said to be fuzzy normal if it satisfies the inequality $M\left(\left(x^{*} a\right)^{*}\left(y^{*} b\right)\right) \geq$ $\min \left\{\mathrm{M}\left(\mathrm{x}^{*} \mathrm{y}\right), \mathrm{M}(\mathrm{a} * \mathrm{~b})\right\}$, for all $\mathrm{a}, \mathrm{b}, \mathrm{x}, \mathrm{y} \in \mathrm{X}$.

Definition (1.8) [14]:

A fuzzy set $A$ in a $B H$-algebra $X$ is said to be a fuzzy subalgebra of $X$ if it satisfies: $A\left(x^{*} y\right) \geq \min \{A(x), A(y)\}$, $\forall \mathrm{x}, \mathrm{y} \in \mathrm{X}$.

Definition (1.9)[6] :

A non constant fuzzy set $A$ of $X$ is a fuzzy filter if

1- $\quad \mathrm{A}(\mathrm{x} \wedge \mathrm{y}) \geq \min \{\mathrm{A}(\mathrm{x}), \mathrm{A}(\mathrm{y})\}$ and $\mathrm{A}(\mathrm{y} \wedge \mathrm{x}) \geq \min \{\mathrm{A}(\mathrm{x}), \mathrm{A}(\mathrm{y})\}$ For any $\mathrm{x}, \mathrm{y} \in \mathrm{X}$.

2- $\quad \mathrm{A}(\mathrm{y}) \geq \mathrm{A}(\mathrm{x})$, when $\mathrm{x} \leq \mathrm{y}$.

Definition (1.10) [ 9]:

Let $\mathrm{X}$ be a BH-algebra, $\mathrm{A}$ be a fuzzy filter of $\mathrm{X}$ and $\mathrm{b} \in \mathrm{X}$. Then $\mathrm{A}$ is called a fuzzy closed filter with respect to an element $\mathrm{b} \in \mathrm{X}$, denoted by a fuzzy b-closed filter of $\mathrm{X}$, if $\mathrm{A}\left(\mathrm{b}^{*}\left(0^{*} \mathrm{x}\right)\right) \geq \mathrm{A}(\mathrm{x}), \forall \mathrm{x} \in \mathrm{X}$.

Definition (1.11)[9] :

Let $\mathrm{X}$ be a $\mathrm{BH}$-algebra and $\mathrm{A}$ be a fuzzy filter of $\mathrm{X}$. Then $\mathrm{A}$ is called a fuzzy completely closed filter ,if $\mathrm{A}\left(\mathrm{x}^{*} \mathrm{y}\right) \geq$ $\min \{\mathrm{A}(\mathrm{x}), \mathrm{A}(\mathrm{y})\} \forall \mathrm{x}, \mathrm{y} \in \mathrm{X}$. 


\section{Definition (1.12) [5]:}

A fuzzy subset A of a $\mathrm{BH}$-algebra $\mathrm{X}$ is said to be a fuzzy ideal if and only if:

1) For any $x \in X, A(0) \geq A(x)$.

2) For any $x, y \in X, A(x) \geq \min \left\{A\left(x^{*} y\right), A(y)\right\}$.

Definition (1.13)[9] :

Let $\mathrm{X}$ be a BH-algebra and $\mathrm{A}$ be a fuzzy ideal of $\mathrm{X}$. Then $\mathrm{A}$ is called a fuzzy completely closed ideal ,if $\mathrm{A}(\mathrm{X} * \mathrm{y}) \geq$ $\min \{\mathrm{A}(\mathrm{x}), \mathrm{A}(\mathrm{y})\}, \forall \mathrm{x}, \mathrm{y} \in \mathrm{X}$.

Definition (1.14)[9] :

Let $\mathrm{X}$ be a BH-algebra and A be a fuzzy ideal of $\mathrm{X}$. Then $\mathrm{A}$ is called a fuzzy completely closed ideal with respect to an element $\mathrm{b} \in \mathrm{X}$, denoted by a fuzzy b-completely closed ideal of $\mathrm{X}$, if $\mathrm{A}\left(\mathrm{b}^{*}\left(\mathrm{x}^{*} \mathrm{y}\right)\right) \geq \min \{\mathrm{A}(\mathrm{x}), \mathrm{A}(\mathrm{y})\} \forall \mathrm{x}, \mathrm{y} \in \mathrm{X}$.

Theorem (1.15)[9]:

Let $\mathrm{X}$ be a $\mathrm{BH}$-algebra and $\mathrm{A}$ be a fuzzy set. Then $\mathrm{A}$ is a fuzzy filter if and only if $\mathrm{A}^{\prime}(\mathrm{x})=\mathrm{A}(\mathrm{x})+1-\mathrm{A}(0)$ is a fuzzy filter.

Theorem ( 1.16 )[9]:

Let $\mathrm{X}$ be an associative $\mathrm{BH}$-algebra. Then every fuzzy normal set of $\mathrm{X}$ is a fuzzy filter.

Proposition (1.17)[9] :

Let $\mathrm{X}$ be a BH-algebra and $\mathrm{A}$ is a fuzzy completely closed filter then $\mathrm{A}(0) \geq \mathrm{A}(\mathrm{x}) \forall \mathrm{x} \in \mathrm{X}$.

Proposition(1.18)[9] :

Let $\mathrm{X}$ be a BH-algebra. If $\mathrm{M}$ is a fuzzy normal set, then $\mathrm{M}(0) \geq \mathrm{M}(\mathrm{x}) \forall \mathrm{x} \in \mathrm{X}$.

\section{MAIN RESULTS}

In this section, we define the a fuzzy completely closed filter with respect to an element, and link the notion with another notions in $\mathrm{BH}$-algebra.

Definition ( 2.1 ): Let X be a BH-algebra and A be a fuzzy filter of X. Then A is called a fuzzy completely closed Filter with respect to an element $\mathrm{b} \in \mathrm{X}$, denoted by a fuzzy b-completely closed Filter of $\mathrm{X}$, if $\mathrm{A}\left(\mathrm{b}^{*}\left(\mathrm{x}^{*} \mathrm{y}\right)\right) \geq$ $\min \{\mathrm{A}(\mathrm{x}), \mathrm{A}(\mathrm{y})\} \forall \mathrm{x}, \mathrm{y} \in \mathrm{F}$.

Example ( 2.2 ):

Let $\mathrm{X}=\{1,2,3\}$ be a BH-algebra, with the following table:

\begin{tabular}{|l|l|l|l|}
\hline$*$ & 0 & 1 & 2 \\
\hline 0 & 0 & 1 & 2 \\
\hline 1 & 1 & 0 & 1 \\
\hline 2 & 2 & 2 & 0 \\
\hline
\end{tabular}

The fuzzy filter A which is defined by $: A(x)=\left\{\begin{array}{cc}0.6 & x=0,2 \\ 0.3 & x=1\end{array}\right.$ is a fuzzy 2-completely closed Filter of $\mathrm{X}$, since

$$
\begin{aligned}
& \mathrm{A}(2 *(0 * 0))=\mathrm{A}(2 * 0)=\mathrm{A}(2)=0.6 \geq \min \{\mathrm{A}(0), \mathrm{A}(0)\}=0.6 \\
& \mathrm{~A}(2 *(0 * 1))=\mathrm{A}(2 * 1)=\mathrm{A}(2)=0.6 \geq \min \{\mathrm{A}(0), \mathrm{A}(1)\}=0.3 \\
& \mathrm{~A}(2 *(0 * 2))=\mathrm{A}(2 * 2)=\mathrm{A}(0)=0.6 \geq \min \{\mathrm{A}(0), \mathrm{A}(2)\}=0.6 \\
& \mathrm{~A}(2 *(1 * 0))=\mathrm{A}(2 * 1)=\mathrm{A}(2)=0.6 \geq \min \{\mathrm{A}(1), \mathrm{A}(0)\}=0.3 \\
& \mathrm{~A}(2 *(1 * 1))=\mathrm{A}(2 * 0)=\mathrm{A}(2)=0.6 \geq \min \{\mathrm{A}(1), \mathrm{A}(1)\}=0.3 \\
& \mathrm{~A}(2 *(1 * 2))=\mathrm{A}(2 * 1)=\mathrm{A}(2)=0.6 \geq \min \{\mathrm{A}(1), \mathrm{A}(2)\}=0.3 \\
& \mathrm{~A}(2 *(2 * 0))=\mathrm{A}(2 * 2)=\mathrm{A}(0)=0.6 \geq \min \{\mathrm{A}(2), \mathrm{A}(0)\}=0.6 \\
& \mathrm{~A}(2 *(2 * 1))=\mathrm{A}(2 * 2)=\mathrm{A}(0)=0.6 \geq \min \{\mathrm{A}(2), \mathrm{A}(1)\}=0.3 \\
& \mathrm{~A}(2 *(2 * 2))=\mathrm{A}(2 * 0)=\mathrm{A}(2)=0.6 \geq \min \{\mathrm{A}(2), \mathrm{A}(2)\}=0.6
\end{aligned}
$$


Theorem ( 2.3 ):Let $X$ be BH-algebra such that if $x^{*} y=0$ implies $\mathrm{x}=\mathrm{y} \forall \mathrm{x}, \mathrm{y} \in \mathrm{X}$. Then every fuzzy b-completely closed filter is a fuzzy filter .

Proof : Let A be a fuzzy b-completely closed filter and $\mathrm{x}, \mathrm{y} \in \mathrm{X}$.

1) $\mathrm{A}\left(\mathrm{x}^{*}\left(\mathrm{x}^{*} \mathrm{y}\right)\right) \geq \min \{\mathrm{A}(\mathrm{x}), \mathrm{A}(\mathrm{y})\} \quad$ [Since $\mathrm{A}$ is a fuzzy b-completely closed filter]

Similarly, $\mathrm{A}(\mathrm{y} *(\mathrm{y} * \mathrm{x})) \geq \min \{\mathrm{A}(\mathrm{x}), \mathrm{A}(\mathrm{y})\}$

2)Let $x \leq y$

$\Rightarrow \mathrm{x} * \mathrm{y}=0 \Rightarrow \mathrm{x}=\mathrm{y}$

$\Rightarrow \mathrm{A}(\mathrm{y})=\mathrm{A}(\mathrm{x}) \geq \mathrm{A}(\mathrm{x})$

$\therefore \mathrm{A}$ is a fuzzy filter

Theorem ( 2.4 ):Let X be an associative BH-algebra. Then every fuzzy b- completely closed filter is a fuzzy b-closed filter.

Proof :Let A is fuzzy b- completely closed filter

Now, $0, \mathrm{x} \in \mathrm{F}, \mathrm{b} \in \mathrm{X}$

$\mathrm{A}(\mathrm{b} *(0 * \mathrm{x})) \geq \min \{\mathrm{A}(0), \mathrm{A}(\mathrm{x})\} \quad[\mathrm{A}$ is fuzzy b-completely closed filter, definition (2.1)]

$\mathrm{A}(\mathrm{b} *(\mathrm{x} * \mathrm{y})) \geq \mathrm{A}(\mathrm{x}) \quad[\mathrm{A}(0) \geq \mathrm{A}(\mathrm{x}) \forall \mathrm{x} \in \mathrm{X}$, Proposition $(1.17)]$

$\therefore \mathrm{A}$ is a fuzzy b-closed filter.

Proposition ( 2.5 ):Let $\mathrm{X}$ be an associative BH-algebra. Then every fuzzy normal set $\forall \mathrm{b} \in \mathrm{X}$,s.t $(\mathrm{M}(\mathrm{b})=\mathrm{M}(0))$ is a fuzzy b-completely closed filter.

Proof :Let $\mathrm{M}$ be a fuzzy normal set.

$\Rightarrow \mathrm{M}$ is a fuzzy filter [ (1.16)]

Now,Let $\mathrm{x}, \mathrm{y} \in \mathrm{M}, \mathrm{b} \in \mathrm{X}$

$$
\begin{array}{rlrl}
\mathrm{M}(\mathrm{b} *(\mathrm{x} * \mathrm{y})) & =\mathrm{M}\left(\mathrm{b}^{*}((\mathrm{x} * \mathrm{y}) *(0 * 0))\right) \\
& =\mathrm{M}\left(\left(\mathrm{b} *\left(\mathrm{x}^{*} \mathrm{y}\right)\right)^{*}(0 * 0)\right) \\
\geq & \min \{\mathrm{M}(\mathrm{b}), \mathrm{M}((\mathrm{x} * \mathrm{y})\} & {[\text { Since } \mathrm{M} \text { is a fuzzy normal set, definition (1.7)] }} \\
\geq & \min \left\{\mathrm{M}(0), \mathrm{M}\left(\left(\mathrm{x}^{*} \mathrm{y}\right)\right\}\right. & {[\mathrm{M}(\mathrm{b})=\mathrm{M}(0)]} \\
= & \mathrm{M}((\mathrm{x} * \mathrm{y}) & {[\mathrm{A}(0) \geq \mathrm{A}(\mathrm{x}) \forall \mathrm{x} \in \mathrm{X}, \text { Proposition }(1.18)]} \\
\geq & \min \{\mathrm{M}(\mathrm{x}), \mathrm{M}(\mathrm{y})\}[\text { Since } \mathrm{M} \text { is a fuzzy normal set definition }(1.7)]
\end{array}
$$

$\therefore \mathrm{M}$ is a fuzzy b-completely closed filter.

Proposition ( 2.6 ):Let $\mathrm{X}$ be a BH-algebra and $\mathrm{A}$ is a fuzzy b- completely closed filter. Then $\mathrm{A} \alpha$ is a b- completely closed filter $\forall \alpha \in(0,1]$.

Proof :Let A be a fuzzy b- completely closed filter.

To prove $\mathrm{A} \alpha$ is a filter,

1)Let $\mathrm{x}, \mathrm{y} \in \mathrm{A} \alpha$

$\Rightarrow \mathrm{A}(\mathrm{x}) \geq \alpha, \mathrm{A}(\mathrm{y}) \geq \alpha$

$\Rightarrow \min \{\mathrm{A}(\mathrm{x}), \mathrm{A}(\mathrm{y})\} \geq \alpha$.

but $\mathrm{A}\left(\mathrm{x}^{*}\left(\mathrm{x}^{*} \mathrm{y}\right)\right) \geq \min \{\mathrm{A}(\mathrm{x}), \mathrm{A}(\mathrm{y})\} \quad$ [Since $\mathrm{A}$ is a fuzzy filter, definition (1.9)]

$\Rightarrow \mathrm{A}\left(\mathrm{x}^{*}\left(\mathrm{x}^{*} \mathrm{y}\right)\right) \geq \alpha$,

$\therefore \mathrm{x}^{*}\left(\mathrm{x}^{*} \mathrm{y}\right) \in \mathrm{A} \alpha$

Similarly,

$\mathrm{y}^{*}\left(\mathrm{y}^{*} \mathrm{x}\right) \in \mathrm{A} \alpha$

2)Let $\mathrm{x} \in \mathrm{A} \alpha$ and $\mathrm{x} * \mathrm{y}=0$

$\Rightarrow \mathrm{A}(\mathrm{x}) \geq \alpha$. 
But $A(y) \geq A(x) \quad$ [Since $A$ is a fuzzy filter and $x \leq y$., definition (1.9)]

$\Rightarrow \mathrm{A}(\mathrm{y}) \geq \alpha$,

$\Rightarrow \mathrm{y} \in \mathrm{A} \alpha$

$\therefore$ A $\alpha$ is a filter

Now,Let $\mathrm{x}, \mathrm{y} \in \mathrm{F}, \mathrm{b} \in \mathrm{X}, \mathrm{x}, \mathrm{y} \in \mathrm{A} \alpha$

$\Rightarrow \mathrm{A}(\mathrm{x}) \geq \alpha$.

$\Rightarrow \mathrm{A}(\mathrm{y}) \geq \alpha$.

$\Rightarrow \min \{\mathrm{A}(\mathrm{x}), \mathrm{A}(\mathrm{y})\} \geq \alpha$

but $\mathrm{A}\left(\mathrm{b} *\left(\mathrm{x}^{*} \mathrm{y}\right)\right) \geq \min \{\mathrm{A}(\mathrm{x}), \mathrm{A}(\mathrm{y})\} \quad$ [Since $\mathrm{A}$ is a fuzzy b-completely closed filter, definition (2.1)]

$\Rightarrow \mathrm{A}(\mathrm{b} *(\mathrm{x} * \mathrm{y})) \geq \alpha$

$\Rightarrow \mathrm{b}^{*}(\mathrm{x} * \mathrm{y}) \in \mathrm{A} \alpha$

$\therefore \mathrm{A} \alpha$ is a b- completely closed filter $\forall \alpha \in(0,1]$

Proposition( 2.7 ): Let $\mathrm{X}$ be a $\mathrm{BH}$-algebra and A be a fuzzy b- completely closed filter. Then the set $\mathrm{X}_{\mathrm{A}}=\{\mathrm{x} \in \mathrm{X}$ : $\mathrm{A}(\mathrm{x})=\mathrm{A}(0)\}$ is a $\mathrm{b}$ - completely closed filter.

Proof :Let A be a fuzzy filter,

Since $\mathrm{A}(0)=\mathrm{A}(0)$

$\therefore 0 \in \mathrm{X}_{\mathrm{A}}$

$\therefore \mathrm{X}_{\mathrm{A}}$ is a non-empty set

1) Let $x, y \in X_{A}$

$$
\begin{aligned}
& \Rightarrow \mathrm{A}(\mathrm{x})=\mathrm{A}(\mathrm{y})=\mathrm{A}(0) \\
& \Rightarrow \min \{\mathrm{A}(\mathrm{x}), \mathrm{A}(\mathrm{y})\}=\mathrm{A}(0)
\end{aligned}
$$

But $\mathrm{A}(\mathrm{x} *(\mathrm{x} * \mathrm{y})) \geq \min \{\mathrm{A}(\mathrm{x}), \mathrm{A}(\mathrm{y})\}=\mathrm{A}(0) \quad$ [Since $\mathrm{A}$ is a fuzzy filter. definition (1.9)]

$\therefore \mathrm{A}(\mathrm{x} *(\mathrm{x} * \mathrm{y})) \geq \mathrm{A}(0)$

But $\mathrm{A}(0) \geq \mathrm{A}\left(\mathrm{x}^{*}\left(\mathrm{x}^{*} \mathrm{y}\right)\right) \quad$ [Since $\mathrm{A}$ is a fuzzy completely closed filter. definition (1.11)]

$\therefore \mathrm{A}(\mathrm{x} *(\mathrm{x} * \mathrm{y}))=\mathrm{A}(0)$

$\therefore \mathrm{x}^{*}(\mathrm{x} * \mathrm{y}) \in \mathrm{X}_{\mathrm{A}}$

Similarly,

$$
\mathrm{y} *(\mathrm{y} * \mathrm{x}) \in \mathrm{X}_{\mathrm{A}}
$$

2)Let $x \in X_{A}, x \leq y$

$\Rightarrow \mathrm{A}(\mathrm{y}) \geq \mathrm{A}(\mathrm{x})=\mathrm{A}(0) \quad[$ Since $\mathrm{A}$ is a fuzzy filter, definition (1.9)]

But $\mathrm{A}(0) \geq \mathrm{A}(\mathrm{y}), \quad$ [Since $\mathrm{A}$ is a fuzzy completely closed filter., definition (1.11)]

$\therefore \mathrm{A}(\mathrm{y})=\mathrm{A}(0)$

$\therefore \mathrm{y} \in \mathrm{X}_{\mathrm{A}}$

$\therefore \mathrm{X}_{\mathrm{A}}$ is a filter.

Now,Let $x, y \in F, b \in X_{A}$

$\Rightarrow \mathrm{A}(\mathrm{x})=\mathrm{A}(\mathrm{y})=\mathrm{A}(0)$

$\Rightarrow \min \{\mathrm{A}(\mathrm{x}), \mathrm{A}(\mathrm{y})\}=\mathrm{A}(0)$

But $\mathrm{A}\left(\mathrm{b} *\left(\mathrm{x}^{*} \mathrm{y}\right)\right) \geq \min \{\mathrm{A}(\mathrm{x}), \mathrm{A}(\mathrm{y})\}=\mathrm{A}(0)$ [Since $\mathrm{A}$ is a fuzzy b-completely closed filter definition (2.1) ]

$\therefore \mathrm{A}(\mathrm{x} * \mathrm{y}) \geq \mathrm{A}(0)$ 
But $\mathrm{A}(0) \geq \mathrm{A}(\mathrm{x} * \mathrm{y})$

[Since A is a fuzzy completely closed filter, definition (1.11)]

$\therefore \mathrm{A}(\mathrm{b} *(\mathrm{x} * \mathrm{y}))=\mathrm{A}(0)$

$\therefore \mathrm{b}^{*}\left(\mathrm{x}^{*} \mathrm{y}\right) \in \mathrm{X}_{\mathrm{A}}$

$\therefore \mathrm{X}_{\mathrm{A}}$ is a b-completely closed filter

Proposition ( 2.8 ): Let $\{\mathrm{Ai}: \mathrm{i} \in \Gamma\}$ be a family of fuzzy b-completely closed filter of a BH-algebra X. Then $\left(\bigcap_{i \in \Gamma} A_{i}\right)$ is a fuzzy b-completely closed filter of $\mathrm{X}$.

Proof :

To prove that $\left(\bigcap_{i \in \Gamma} A_{i}\right)$ is a fuzzy filter,

(1) Let $\mathrm{x}, \mathrm{y} \in \mathrm{X}$.

$\left(\bigcap_{i \in \Gamma^{r}} A_{i}\right)(\mathrm{x} *(\mathrm{x} * \mathrm{y}))=\inf \{\operatorname{Ai}((\mathrm{x} *(\mathrm{x} * \mathrm{y}))), \mathrm{i} \in \Gamma\}$

$\geq \inf \left\{\min \{\operatorname{Ai}(x), \operatorname{Ai}(y), i \in \Gamma\} \quad\right.$ [Since $A_{i}$ is a fuzzy filter, $\forall i \in \Gamma$, definition (1.9)]

Similarly $\left(\bigcap_{i \in \Gamma} A_{i}\right)\left(\mathrm{y}^{*}\left(\mathrm{y}^{*} \mathrm{x}\right)\right)$

(2) Let $\mathrm{x} \in \mathrm{X}$ and $\mathrm{x} \leq \mathrm{y}$

$\Rightarrow\left(\bigcap_{i \in \Gamma} \boldsymbol{A}_{\boldsymbol{i}}\right)(\mathrm{x})=\inf \{\operatorname{Ai}(\mathrm{x}), \mathrm{i} \in \Gamma\}$

$=\left(\bigcap_{i \in \Gamma} A_{i}\right)(\mathrm{y}) \quad$ inf $\left.\{\operatorname{Ai}(\mathrm{y})\}, \mathrm{i} \in \Gamma\right\} \quad$ Since Ai is a fuzzy filter, $\forall \mathrm{i} \in \Gamma$, definition (1.9)]

$\Rightarrow\left(\bigcap_{i \in I} A_{i}\right)$ is a fuzzy filter

To prove that $\left(\bigcap_{i \in \Gamma^{-}} A_{i}\right)$ is a fuzzy b-completely closed filter of $\mathrm{X}$
Let $\mathrm{x}, \mathrm{y} \in \mathrm{F}, \mathrm{b} \in \mathrm{X}$

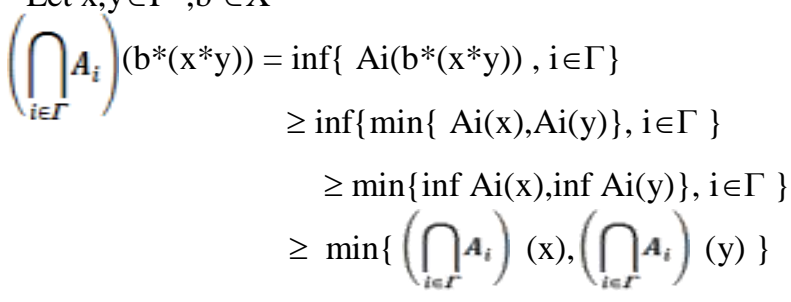

$\Rightarrow\left(\bigcap_{i \in \Gamma^{-}} A_{i}\right)(\mathrm{b} *(\mathrm{x} * \mathrm{y})) \geq \min \left\{\left(\bigcap_{i \in \Gamma} A_{i}\right)(\mathrm{x}),\left(\bigcap_{i \in \Gamma^{\prime}} A_{i}\right)(\mathrm{y})\right\} \forall \mathrm{x}, \mathrm{y} \in \mathrm{F}$

Therefore, $\left(\bigcap_{i \in I} A_{i}\right)$ is a fuzzy b-completely closed filter of $\mathrm{X}$.

Proposition ( 2.9):
Let $\{\mathrm{Ai}: \mathrm{i} \in \Gamma\}$ be a family of fuzzy b-completely closed filter of a $\mathrm{BH}$-algebra $\mathrm{X}$. Then $\left(\bigcup_{i \in \Gamma} A_{i}\right)$ is a fuzzy b-completely closed filter of $\mathrm{X}$.

Proof :

To prove that $\left(\bigcup_{i \in T^{-}} A_{i}\right)$ is a fuzzy filter,

(1) Let $\mathrm{x}, \mathrm{y} \in \mathrm{X}$.

$$
\begin{array}{r}
\left(\bigcup_{i \in \Gamma} \boldsymbol{A}_{\boldsymbol{i}}\right)\left(\mathrm{x}^{*}\left(\mathrm{x}^{*} \mathrm{y}\right)\right)=\sup \left\{\operatorname{Ai}\left(\left(\mathrm{x}^{*}\left(\mathrm{x}^{*} \mathrm{y}\right)\right)\right), \mathrm{i} \in \Gamma\right\} \\
\geq \sup \{\min \{\operatorname{Ai}(\mathrm{x}), \operatorname{Ai}(\mathrm{y}), \mathrm{i} \in \Gamma\}
\end{array}
$$

[Since $\mathrm{A}_{\mathrm{i}}$ is a fuzzy filter, $\forall \mathrm{i} \in \Gamma$, definition (1.9)]

But $\{\mathrm{Ai}: \mathrm{i} \in \Gamma\}$ is a chain $\Rightarrow$ there exist $\mathrm{j} \in \Gamma$ such that 
$\sup \left\{\min \left\{\operatorname{Ai}\left(x^{*} y\right), \operatorname{Ai}(y)\right\}, i \in \Gamma\right\}=\min \{\operatorname{Aj}(x), \operatorname{Aj}(y)\}$

$$
=\min \{\sup \{\operatorname{Ai}(x), i \in \Gamma\}, \sup \{\operatorname{Ai}(y), i \in \Gamma\}\}
$$

Similarly $\left(\bigcup_{i \in T} A_{i}\right)\left(\mathrm{y}^{*}\left(\mathrm{y}^{*} \mathrm{x}\right)\right)$

(2) Let $x \in X$ and $x \leq y$

$\Rightarrow\left(\bigcup_{i \in \Gamma} \boldsymbol{A}_{i}\right)(\mathrm{x})=\sup \{\operatorname{Ai}(\mathrm{x}), \mathrm{i} \in \Gamma\}$

$\geq \sup \{\operatorname{Ai}(\mathrm{y})\}, \mathrm{i} \in \Gamma\} \quad$ [Since $\mathrm{Ai}$ is a fuzzy filter, $\forall \mathrm{i} \in \Gamma$, definition (1.9)]

$=\left(\bigcup_{i \in r^{r}} A_{i}\right)(\mathrm{y})$

$\Rightarrow\left(\bigcup_{i \in S^{*}} A_{i}\right)$ is a fuzzy filter

To prove that $\left(\bigcup_{i \in T^{-}} A_{i}\right)$ is a fuzzy b-completely closed filter of $\mathrm{X}$

Let $\mathrm{x}, \mathrm{y} \in \mathrm{F}, \mathrm{b} \in \mathrm{X}$

$$
\begin{aligned}
& \left(\bigcup_{i \in \Gamma^{*}} \boldsymbol{A}_{\boldsymbol{i}}\right)\left(\mathrm{b}^{*}\left(\mathrm{x}^{*} \mathrm{y}\right)\right)=\sup \left\{\operatorname{Ai}\left(\mathrm{b}^{*}\left(\mathrm{x}^{*} \mathrm{y}\right)\right), \mathrm{i} \in \Gamma\right\} \\
& \geq \sup \{\min \{\operatorname{Ai}(\mathrm{x}), \operatorname{Ai}(\mathrm{y})\}, \mathrm{i} \in \Gamma\} \\
& \geq \min \{\sup \operatorname{Ai}(x), \inf \operatorname{Ai}(y)\}, i \in \Gamma\} \\
& \geq \min \left\{\left(\bigcup_{i \in \Gamma^{\top}} A_{i}\right)(\mathrm{x}),\left(\bigcup_{i \in \Gamma^{\top}} A_{i}\right)(\mathrm{y})\right\}
\end{aligned}
$$

Therefore $\left(\bigcup_{i \in \Gamma^{-}} \boldsymbol{A}_{\boldsymbol{i}}\right)$ is a fuzzy b-completely closed filter of $\mathrm{X}$.

Proposition ( 2.10$)$ :
Let $\{$ Ai:i $\in \Gamma\}$ be a family of fuzzy b-closed filter of a BH-algebra X. Then $\left(\bigcap_{i \in \Gamma} A_{i}\right)$ is a fuzzy b-closed filter of X.

Proof :

$\left(\bigcap_{i \in \Gamma} A_{i}\right)$ is a fuzzy filter $\quad$ [proposition (2.8)]

$\left(\bigcap_{i \in \Gamma} A_{i}\right) \begin{array}{r}\text { to prove is a fuzzy b-closed filter } \\ \text { let } \mathrm{b} \in \mathrm{X}, \mathrm{x} \in \mathrm{F}\end{array}$

$\left(\bigcap_{i \in \Gamma} A_{i}\right)(\mathrm{b} *(0 * \mathrm{x}))=\inf \{\operatorname{Ai}(\mathrm{b} *(0 * \mathrm{x})), \mathrm{i} \in \Gamma\}$

$\geq \inf \{\operatorname{Ai}(x), i \in \Gamma\}$

$\geq\left(\bigcap_{i \in \Gamma} A_{i}\right)(\mathrm{x})$

$\Rightarrow\left(\bigcap_{i \in \Gamma} A_{i}\right)(\mathrm{b} *(0 * \mathrm{x})) \geq\left(\bigcap_{i \in \Gamma} A_{i}\right)(\mathrm{x})$

Therefore, $\left(\bigcap_{i \in T} A_{i}\right)$ is a fuzzy b- closed filter of X.

Proposition ( 2.11$)$ :

Let $\{$ Ai:i $\in \Gamma\}$ be a family of fuzzy b-closed filter of a BH-algebra X. Then $\left(\bigcup_{i \in \Gamma} A_{i}\right)$ is a fuzzy b-closed filter of X. Proof :

$\left(\bigcup_{i \in \Gamma} \boldsymbol{A}_{i}\right)$ is a fuzzy filter $\quad$ [proposition (2.9)]

$\left(\bigcup_{i \in \Gamma} \boldsymbol{A}_{i}\right)$ to prove is a fuzzy b-closed filter 


$$
\begin{aligned}
& \begin{aligned}
\left(\bigcup_{i \in \Gamma} A_{i}\right)\left(\mathrm{b}^{*}\left(0^{*} \mathrm{x}\right)\right) & =\sup \left\{\operatorname{Ai}\left(\mathrm{b}^{*}\left(0^{*} \mathrm{x}\right)\right), \mathrm{i} \in \Gamma\right\} \\
& \geq \sup \{\operatorname{Ai}(\mathrm{x}), \mathrm{i} \in \Gamma\}
\end{aligned} \\
& \geq\left(\bigcup_{i \in I^{\prime}} A_{i}\right)(\mathrm{x}) \\
& \Rightarrow\left(\bigcup_{i \in \Gamma} A_{i}\right)(\mathrm{b} *(0 * \mathrm{x})) \geq\left(\bigcup_{i \in \Gamma} A_{i}\right)(\mathrm{x}) \\
& \text { Therefore, }\left(\bigcup_{i \in \Gamma} A_{i}\right) \text { is a fuzzy b-closed filter of } \mathrm{X} \text {. }
\end{aligned}
$$

\section{Proposition ( 2.12 ):}

Let $\mathrm{X}$ be $\mathrm{BH}$-algebra and $\mathrm{A}$ be a fuzzy set of $\mathrm{X}$. Then $\mathrm{A}$ is a fuzzy b-completely closed filter if and only if $\mathrm{A}^{\prime}(\mathrm{x})=\mathrm{A}(\mathrm{x})+1-\mathrm{A}(0)$ is a fuzzy $\mathrm{b}$-completely closed filter.

Proof :

Let A be a fuzzy b-completely closed filter,

$\Rightarrow \mathrm{A}$ is a fuzzy filter. [Proposition (2.3)]

$\Rightarrow \mathrm{A}^{\prime}$ is a fuzzy filter. [By theorem(1.15)]

Now, Let $\mathrm{x}, \mathrm{y} \in \mathrm{A}, \mathrm{b} \in \mathrm{X}$

$$
\begin{aligned}
& \begin{array}{l}
\mathrm{A}^{\prime}\left(\mathrm{b}^{*}\left(\mathrm{x}^{*} \mathrm{y}\right)\right)=\mathrm{A}\left(\mathrm{b}^{*}\left(\mathrm{x}^{*} \mathrm{y}\right)\right)+1-\mathrm{A}(0) \\
\quad \geq \min \{\mathrm{A}(\mathrm{x}), \mathrm{A}(\mathrm{y})\}+1-\mathrm{A}(0) \quad[\text { Since } \mathrm{A} \text { is a fuzzy b-completely closed filter }] \\
\quad \geq \min \{\mathrm{A}(\mathrm{x})+1-\mathrm{A}(0), \mathrm{A}(\mathrm{y})+1-\mathrm{A}(0)\} \\
\quad \geq \min \left\{\mathrm{A}^{\prime}(\mathrm{x}), \mathrm{A}^{\prime}(\mathrm{y})\right\}
\end{array} \\
& \therefore \mathrm{A}^{\prime}(\mathrm{x}) \geq \min \left\{\mathrm{A}^{\prime}(\mathrm{x}), \mathrm{A}^{\prime}(\mathrm{y})\right\} \\
& \therefore \mathrm{A}^{\prime} \text { is a fuzzy b-completely closed filter }
\end{aligned}
$$

Conversely

Let A' be a fuzzy b-completely closed filter,

$\Rightarrow \mathrm{A}^{\prime}$ is a fuzzy filter. [By theorem(1.15)]

$\Rightarrow \mathrm{A}$ is a fuzzy filter. $\quad$ [By theorem(1.15)]

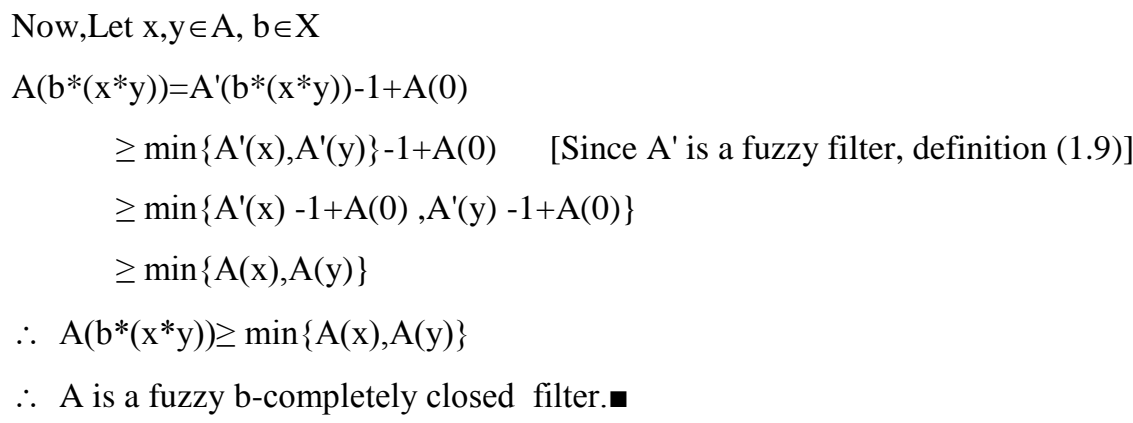

Proposition ( 2.13 ): Let $\mathrm{X}$ be BH-algebra and A be a fuzzy set of $\mathrm{X}$. Then every fuzzy completely closed filter is a fuzzy b-completely closed ideal, $\forall \mathrm{b} \in \mathrm{X}, \mathrm{A}(\mathrm{b})=\mathrm{A}(0)$.

Proof : Let A be a fuzzy completely closed filter.

To prove A is a fuzzy ideal,

1) $\mathrm{A}(0) \geq \mathrm{A}(\mathrm{x}) \forall \mathrm{x} \in \mathrm{X} \quad$ [Proposition (1.16)]

2) $\mathrm{A}(\mathrm{x})=\mathrm{A}(\mathrm{x} * 0)=\mathrm{A}(\mathrm{x} *(\mathrm{y} * \mathrm{y}))$ $=\mathrm{A}((\mathrm{x} * \mathrm{y}) * \mathrm{y})) \quad[$ Since $\mathrm{X}$ is an associative. By definition(1.5)] 
$\geq \min \{\mathrm{A}(\mathrm{x} * \mathrm{y}), \mathrm{A}(\mathrm{y})\}$ [Since $\mathrm{A}$ is a fuzzy completely closed filter By definition(1.11) ]

$\therefore \mathrm{A}$ is a fuzzy ideal.

$\mathrm{A}(\mathrm{b} *(\mathrm{x} * \mathrm{y})) \geq \min \left\{\mathrm{A}(\mathrm{b}), \mathrm{A}\left(\mathrm{x}^{*} \mathrm{y}\right)\right\}[\mathrm{A}$ is a fuzzy completely closed filter. By definition(1.11)]

$$
\begin{aligned}
& \geq \min \left\{\mathrm{A}(0), \mathrm{A}\left(\mathrm{x}^{*} \mathrm{y}\right)\right\} \\
& \geq \mathrm{A}\left(\mathrm{x}^{*} \mathrm{y}\right) \\
& \geq \min \{\mathrm{A}(\mathrm{x}), \mathrm{A}(\mathrm{y})\}
\end{aligned}
$$

$\therefore \mathrm{A}$ is a fuzzy b-completely closed ideal.

\section{Proposition ( 2.14 ):}

Let $X$ be $B H$-algebra such that if $x^{*} y=0$ implies $x=y \forall x, y \in X$. Then every fuzzy sub algebra is a fuzzy filter.

Proof :Let A be a fuzzy sub algebra and $\mathrm{x}, \mathrm{y} \in \mathrm{X}$.

1) $\mathrm{A}(\mathrm{x} *(\mathrm{x} * \mathrm{y})) \geq \min \{\mathrm{A}(\mathrm{x}), \mathrm{A}(\mathrm{x} * \mathrm{y})\} \quad$ [Since $\mathrm{A}$ is a fuzzy sub algebra, definition (1.8)]

$$
\begin{aligned}
& \text { If } \min \left\{\mathrm{A}(\mathrm{x}), \mathrm{A}\left(\mathrm{x}^{*} \mathrm{y}\right)\right\}=\mathrm{A}(\mathrm{x}) \geq \min \{\mathrm{A}(\mathrm{x}), \mathrm{A}(\mathrm{y})\} \\
& \text { If } \min \left\{\mathrm{A}(\mathrm{x}), \mathrm{A}\left(\mathrm{x}^{*} \mathrm{y}\right)\right\}=\mathrm{A}\left(\mathrm{x}^{*} \mathrm{y}\right) \geq \min \{\mathrm{A}(\mathrm{x}), \mathrm{A}(\mathrm{y})\}
\end{aligned}
$$

$\therefore \mathrm{A}\left(\mathrm{x}^{*}(\mathrm{x} * \mathrm{y})\right) \geq \min \{\mathrm{A}(\mathrm{x}), \mathrm{A}(\mathrm{y})\}$

Similarly, $\mathrm{A}\left(\mathrm{y}^{*}\left(\mathrm{y}^{*} \mathrm{x}\right)\right) \geq \min \{\mathrm{A}(\mathrm{x}), \mathrm{A}(\mathrm{y})\}$

2)Let $x \leq y$

$\Rightarrow \mathrm{x} * \mathrm{y}=0 \Rightarrow \mathrm{x}=\mathrm{y}$

$\Rightarrow \mathrm{A}(\mathrm{y})=\mathrm{A}(\mathrm{x}) \geq \mathrm{A}(\mathrm{x})$

$\therefore$ A is a fuzzy filter

Theorem ( 2.15 ):

Let $\mathrm{X}$ be $\mathrm{BH}$-algebra such that $\mathrm{x} * \mathrm{y}=0$ implies $\mathrm{x}=\mathrm{y} \forall \mathrm{x}, \mathrm{y} \in \mathrm{X}$. Then every fuzzy sub algebra is a fuzzy $\mathrm{b}$-completely closed filter, $\forall \mathrm{b} \in \mathrm{X}$ such that $\mathrm{A}(\mathrm{b})=\mathrm{A}(0)$.

Proof :

A is a fuzzy filter [proposition(2.14)]

$\mathrm{A}\left(\mathrm{b} *\left(\mathrm{x}^{*} \mathrm{y}\right)\right) \geq \min \left\{\mathrm{A}(\mathrm{b}), \mathrm{A}\left(\mathrm{x}^{*} \mathrm{y}\right)\right\} \quad[\mathrm{A}$ is a fuzzy sub algebra, definition (1.8)]

$$
\begin{aligned}
& \geq \min \left\{\mathrm{A}(0), \mathrm{A}\left(\mathrm{x}^{*} \mathrm{y}\right)\right\} \\
& \geq \mathrm{A}\left(\mathrm{x}^{*} \mathrm{y}\right) \\
& \geq \min \{\mathrm{A}(\mathrm{x}), \mathrm{A}(\mathrm{y})\}
\end{aligned}
$$

$\therefore \mathrm{A}$ is a fuzzy b-completely closed filter.

\section{REFERENCES}

[1] A. B. Saeid, A. Namdar and R.A. Borzooei, "Ideal Theory of BCH-Algebras", World Applied Sciences Journal 7 (11): 1446-1455, 2009.

[2] A. B. Saeid and M. A. Rezvani "On Fuzzy BF-algebras ", International Journal of Fuzzy System, Vol. 4,No. $1,13-25,2009$.

[3] B. Ahmad, "On classification of BCH-algebras", Math. Japonica 35, no. 5, 801-804, 1990.

[4] C. B. Kim and H. S. Kim, "On BG-algebras", Demonstratio Mathematica, Vol.XLI, No 3, 2008.

[5] C. H. Park, "Interval-valued fuzzy ideal in BH-algebras", Advance in fuzzy set and systems 1(3), 231-240, 2006.

[6] C. Lele, C. Wu and T. Mamadou, "Fuzzy Filters in BCI-algebras", IJMMS, 29:1, 47-54, 2002.

[7] C. S. Hoo, "Filters and ideals in BCI-algebra, Math. Japonica 36, 987-997, 1991.

[8] D. Dubois and H. Prade, "FUZZY SETS AND SYSTEMS", ACADEMIC PRESS. INC. (London) LTD., ACADEMIC PRESS. INC. fifth Avenue, New York, 1980. 
[9] H. H. Abass and H. A. Dahham," Some Types of Fuzzy Ideal With Respect To an Element Of a BG-Algebra" Msc. Thesis Kufa university ,2012.

[10] H. H. Abass and H. M. A. Saeed, "The Fuzzy Closed Ideal With Respect To An Element Of a BH-Algebra", Kufa University, Msc thesis, 2011.

[11] J. Neggers and H. S. Kim, "On B-algebras", Mate Vesnik, 54, 21-29, 2002.

[12] L. A. Zadeh, "Fuzzy Sets", Information and control, Vol. 8, PP. 338-353, 1965.

[13] O. G. Xi, "Fuzzy BCK-algebra", Math. Japonica 36, no. 5, 935-942, 1991.

[14] Q. Zhang, E. H. Roh and Y. B. Jun, "On fuzzy BH-algebras", J. Huanggang, Normal Univ. 21(3), 14-19, 2001.

[15] Y. B. Jun and J. Meng, "Fuzzy p-ideals in BCI-algebras", Math. Japon, 40, 271-282, 1994.

[16] Y. B. Jun, "characterization of fuzzy ideal by their level ideals in BCK(BCI)-algebra", Math. Japon., 38, 67-71, 1993.

[17] Y. B. Jun, "Closed fuzzy ideals in BCI-algebras", Math. Japon.ica 38, no. 1, 199-202, 1993.

[18] Y. B. Jun, "Fuzzy closed ideals and fuzzy filters in BCH-algebras", J. Fuzzy Math. 7 , no. 2, 435-444, 1999.

[19] Y. B. Jun, E. H. Roh and H. S. Kim, "On Fuzzy B-algebras", Czechoslovak Mathematical Journal. Japan, 52(127), 375-384, 2002. 